\title{
What impedes performance of students? A cross-sectional study of student perceptions
}

\author{
Chitra Nagaraj ${ }^{1}$, Pradeep B $S^{2}$
}

\section{Introduction and need for the study}

It is globally accepted that training in medical courses is rigorous and requires a lot of hard work. Yates and James (2006) have reported that $10-15 \%$ student intake of each year at Nottingham University Medical School were identified as strugglers. In India, though all students admitted to medical school start off on the same platform, by completing their preuniversity course from a junior college or 12 standard from schools, we find that some students are able to sail through the medical course, while others struggle to complete it.

In a study of under achievement among college students, Balduf (2009) found one of the important reasons for under achievement to be that these students were never taught, nor had they ever taught themselves how to work through challenging situations. Once the student starts performing poorly, many times he/she is not able to get back on track towards an improved performance.

This study was undertaken to identify the factors that affect student performance in a medical school and to obtain a student's and peer's perspective on the reasons for their own good or poor performance.

\section{Material and methods}

Kempegowda Institute of Medical Sciences (KIMS) is a medical college situated in urban

\footnotetext{
${ }^{1}$ Associate Professor, Department of Community Medicine Kempegowda Institute of Medical Sciences, Bangalore, Karnataka, India.

${ }^{2}$ Associate Professor, Department of Community Medicine Rajarajeswari Medical College

Bangalore, Karnataka, India.

Corresponding author

Dr Chitra Nagaraj

Associate Professor, Department of Community Medicine Kempegowda Institute of Medical Sciences,

BSK 2nd Stage, Bangalore, Karnataka, India - 560070

E-mail: drchitranagaraj@gmail.com
}

Bangalore, India. One hundred and twenty students are admitted to this institution every academic year. This cross-sectional study was conducted between October and December 2008. Current students of the college and interns who had graduated with MBBS from this college were considered as study participants. Inclusion criteria were that they should have taken at least one university examination and consented to participate in the study. Such willing and eligible students and interns $(n=413)$ were administered a pretested, self-administered questionnaire to elicit their views (and also views of their peers) on the reasons for their good or poor performance. The questionnaire was pretested on fresh MBBS graduates working as tutors in various departments of KIMS, Bangalore to ensure feasibility and finalize the questionnaire in terms of flow and skip patterns. This data was not analyzed.

\section{Results \& Discussion}

Students attributed good performance (Table 1) to being regular in studies (36\%), having appropriate study skills (23\%), interest in their courses (9\%), and support from family and friends (8\%). Problems within themselves such as not studying regularly, lack of systematic planning and execution, poor time management, poor concentration and studying only prior to the exams were considered major causes for poor performance (59\%). Inability to overcome distractions, problems with inter-personal relationships and adjusting to hostel life were among the social reasons (16\%) for poor performance.

For poor performance of their peers, students perceived problems within the individual (47\%) such as poor understanding of the subject, lack of preparation for the examinations, poor study skills and disinterest in the course. Social causes (18\%) such as inability to overcome distractions and poor interpersonal relationships also contributed for the poor performance of their peers. 
Table 1: Reasons given for student's good performance

\begin{tabular}{clll}
\hline SI No & Reasons & $\begin{array}{l}\text { No. of } \\
\text { Responses* }\end{array}$ & (\%) \\
\hline 1 & Regular in studies & 119 & 23 \\
2 & Good study skills & 075 & 09 \\
3 & Interest in the course & 030 & 08 \\
4 & Support from family and friends & 09 \\
5 & Do not get easily distracted & 026 & 15 \\
6 & Miscellaneous & 030 & 100 \\
\hline & Total & 053 & \\
\hline * 413 students and interns took part in the study & 333 &
\end{tabular}

Balduf (2009) also cites inadequate study skills, poor time management and poor motivation to be important causes for under achievement. The participants in that (Balduf, 2009) felt that improving their own attitudes and behaviour was the best way to reverse under achievement. Balduf also states that in addition to offering study skills courses to underachieving students, colleges should include preemptive strategies for all incoming freshmen, including motivational and time management strategies.

\section{Recommendations}

Most problems cited by the students are modifiable through counseling and intervention. A designated faculty member or an academic counselor would be an appropriate person to talk to the students and help them cope with the stress of examinations and thus be successful in their studies. However, further research studies focusing in-depth on the reasons for these issues would throw light on the appropriate interventions to be planned that would address local problems within the medical school. In addition to such tailor-made interventions based on identification of the underlying/contributing factors, there is also need to study other skills that facilitate learning such as student's general note taking skills, memory and comprehension skills to design a more comprehensive intervention that will make them self-directed life-long learners.

\section{Contribution by authors}

Both the authors contributed to the design and conduct of the study. The first author conducted the study and wrote the draft manuscript. The second author analyzed the data and reviewed the draft.

\section{Conflict of interest}

Authors declare no conflict of interest. Only students who were willing to participate and give consent were included in the study. Ethical clearance was obtained for the study from the Institutional Ethics Committee.

\section{Acknowledgements}

- FAIMER Institute for refining the project idea, periodic feedback and extended advice by PSG FAIMER Regional Institute faculty peers and senior fellows.

- Dean and Principal, Kempegowda Institute of Medical Sciences, Bangalore, for support in conducting the study.

\section{References}

Yates, J. \& James, D. (2006) Predicting the "Strugglers": A case-control study of students at Nottingham University Medical School, British Medical Journal, 332, pp.1009-1013.

Balduf, M. (2009) Underachievement among College Students, Journal of Advanced Academics, 20, 2, pp. 274-294. 